NASA/TM-2005-213892

Electric Propulsion System Modeling for the Proposed Prometheus 1 Mission

Douglas Fiehler

QSS Group, Inc., Cleveland, Ohio

Ryan Dougherty

Jet Propulsion Laboratory, Pasadena, California

David Manzella

Glenn Research Center, Cleveland, Ohio 
Since its founding, NASA has been dedicated to the advancement of aeronautics and space science. The NASA Scientific and Technical Information (STI) Program Office plays a key part in helping NASA maintain this important role.

The NASA STI Program Office is operated by Langley Research Center, the Lead Center for NASA's scientific and technical information. The NASA STI Program Office provides access to the NASA STI Database, the largest collection of aeronautical and space science STI in the world. The Program Office is also NASA's institutional mechanism for disseminating the results of its research and development activities. These results are published by NASA in the NASA STI Report Series, which includes the following report types:

- $\quad$ TECHNICAL PUBLICATION. Reports of completed research or a major significant phase of research that present the results of NASA programs and include extensive data or theoretical analysis. Includes compilations of significant scientific and technical data and information deemed to be of continuing reference value. NASA's counterpart of peerreviewed formal professional papers but has less stringent limitations on manuscript length and extent of graphic presentations.

- TECHNICAL MEMORANDUM. Scientific and technical findings that are preliminary or of specialized interest, e.g., quick release reports, working papers, and bibliographies that contain minimal annotation. Does not contain extensive analysis.

- CONTRACTOR REPORT. Scientific and technical findings by NASA-sponsored contractors and grantees.
- CONFERENCE PUBLICATION. Collected papers from scientific and technical conferences, symposia, seminars, or other meetings sponsored or cosponsored by NASA.

- SPECIAL PUBLICATION. Scientific, technical, or historical information from NASA programs, projects, and missions, often concerned with subjects having substantial public interest.

- TECHNICAL TRANSLATION. Englishlanguage translations of foreign scientific and technical material pertinent to NASA's mission.

Specialized services that complement the STI Program Office's diverse offerings include creating custom thesauri, building customized databases, organizing and publishing research results ... even providing videos.

For more information about the NASA STI Program Office, see the following:

- Access the NASA STI Program Home Page at http://www.sti.nasa.gov

- E-mail your question via the Internet to help@sti.nasa.gov

- Fax your question to the NASA Access Help Desk at 301-621-0134

- Telephone the NASA Access Help Desk at 301-621-0390

- Write to:

NASA Access Help Desk

NASA Center for AeroSpace Information 7121 Standard Drive

Hanover, MD 21076 
NASA/TM-2005-213892

Electric Propulsion System Modeling for the Proposed Prometheus 1 Mission

Douglas Fiehler

QSS Group, Inc., Cleveland, Ohio

Ryan Dougherty

Jet Propulsion Laboratory, Pasadena, California

David Manzella

Glenn Research Center, Cleveland, Ohio

Prepared for the

41st Joint Propulsion Conference and Exhibit

cosponsored by the AIAA, ASME, SAE, and ASEE

Tucson, Arizona, July 10-13, 2005

National Aeronautics and

Space Administration

Glenn Research Center 


\section{Acknowledgments}

NASA's Prometheus Project supported the work described within this paper, in whole or part, as part of the program's technology development and evaluation activities. The authors also thank Melissa Papa for her work generating many of the figures for this paper.

Trade names or manufacturers' names are used in this report for identification only. This usage does not constitute an official endorsement, either expressed or implied, by the National Aeronautics and Space Administration.

Available from

NASA Center for Aerospace Information 7121 Standard Drive

Hanover, MD 21076
National Technical Information Service 5285 Port Royal Road Springfield, VA 22100 


\title{
Electric Propulsion System Modeling for the Proposed Prometheus 1 Mission
}

\author{
Douglas Fiehler \\ QSS Group, Inc. \\ Cleveland, Ohio 44135 \\ Ryan Dougherty \\ Jet Propulsion Laboratory \\ Pasadena, California 91109 \\ David Manzella \\ National Aeronautics and Space Administration \\ Glenn Research Center \\ Cleveland, Ohio 44135
}

\begin{abstract}
The proposed Prometheus 1 spacecraft would utilize nuclear electric propulsion to propel the spacecraft to its ultimate destination where it would perform its primary mission. As part of the Prometheus 1 Phase A studies, system models were developed for each of the spacecraft subsystems that were integrated into one overarching system model. The Electric Propulsion System (EPS) model was developed using data from the Prometheus 1 electric propulsion technology development efforts. This EPS model was then used to provide both performance and mass information to the Prometheus 1 system model for total system trades. Development of the EPS model is described, detailing both the performance calculations as well as its evolution over the course of Phase A through three technical baselines. Model outputs are also presented, detailing the performance of the model and its direct relationship to the Prometheus 1 technology development efforts. These EP system model outputs are also analyzed chronologically showing the response of the model development to the four technical baselines during Prometheus 1 Phase A.
\end{abstract}

\section{Nomenclature}

$e$

$E_{b}$

$f$

$f_{a b}$

$f(\omega)$

$g_{0}$

$I_{S P}$

$J_{b}$

$J_{d}$

$m_{\text {Beam }}$

$m_{\text {Discharge }}$

$m_{i}$

$\dot{m}_{T}$

$\eta$

$\eta_{\alpha}$

$\eta_{\varepsilon}$

$\eta_{\theta}$
Unit Charge, $1.602 \times 10^{-19} \mathrm{C}$

Discharge Losses ( $\mathrm{W}_{\mathrm{e}} / \mathrm{A}$ or eV/ion)

Doubles to Singles Current Ratio

Ratio of Accelerator Grid Current to Beam Current

Coefficient of PP\&C Beam Module Mass Equation $\left(\mathrm{kg} / \mathrm{kW}_{\mathrm{e}} \mathrm{e}^{0.87}\right)$

Acceleration due to Earth's gravity, $9.80665 \mathrm{~m} / \mathrm{s}^{2}$

Specific Impulse (seconds)

Beam Current (A)

Discharge Current (A)

PP\&C Beam Module Mass $(\mathrm{kg})$

PP\&C Discharge Module Mass $(\mathrm{kg})$

Xenon atomic mass, $2.180 \times 10^{-25} \mathrm{~kg}$

Total Mass Flow Rate $(\mathrm{kg} / \mathrm{s})$

Total Thruster Efficiency

Doubles to Singles Correction Factor

Electrical Efficiency

Beam flatness parameter, the ratio of the average to peak current density 


$\begin{array}{ll}\eta_{u} & \text { Propellant Utilization Efficiency } \\ P_{l} & \text { Sum of the Miscellaneous Power Losses }\left(\mathrm{W}_{\mathrm{e}}\right) \\ P & \text { Total Power Into the Thruster }\left(\mathrm{W}_{\mathrm{e}}\right) \\ P_{P P \& C} & \text { Total Power Into the Power Processing \& Control Unit }\left(\mathrm{kW}_{\mathrm{e}}\right) \\ R & \text { R-ratio, ratio of beam plus coupling voltage to beam plus absolute value of accelerator voltage } \\ T & \text { Thrust }(\mathrm{N}) \\ V_{b} & \text { Beam Voltage }(\mathrm{V})\end{array}$

The Prometheus Project, started in 2002 as the Nuclear Systems Initiative, was tasked with developing nuclear electric propulsion (NEP) capability for the National Aeronautics and Space Administration (NASA) civilian space missions ${ }^{1}$. NASA conducted studies from mid-2002 through early 2003 to assess what was then called a Jupiter Icy Moon Tour mission ${ }^{2}$. Early in 2003, Congress appropriated funding to begin studying a Jupiter Icy Moons Orbiter (JIMO) mission ${ }^{1,3}$, which was originally slated as the first mission for this NEP system. Technology tasks were also started as part of the Prometheus Project to develop the reactor ${ }^{1}$, power conversion ${ }^{1,4,5}$, and electric propulsion systems ${ }^{1,6}$.

One task created as part of the Prometheus Project was the System Modeling and Analysis (SM\&A) task. The goal of this task was to develop a system model for the Prometheus 1 spacecraft ${ }^{7}$. This model, containing eight modules representing different subsystems of the spacecraft, the launch vehicle, and mission design, was then used to perform linked analyses of the mission and systems ${ }^{8}$. The Electric Propulsion System (EPS) model, as part of the SM\&A task, was required to accept inputs, such as power level and specific impulse, and provide an EPS designed for the particular inputs. The EPS model would then output parameters needed by the Prometheus system model and other models, such as masses and efficiencies, so that the design could be iterated upon and a converged mission and system solution obtained.

\section{Electric Propulsion System Baseline Designs}

The Prometheus Project had three Technical Baselines that required EPS model development for the JIMO mission. Technical Baseline 2 (TB2) was defined in late 2003 and early 2004, Technical Baseline 2.5 (TB2.5) was defined in the Fall of 2004, and Prometheus Baseline 1 (PB1) was defined in late 2004 and early 2005. TB2 and TB2.5 were the results of the government-only Phase A studies, whereas PB1 incorporated the team from Northrop Grumman Space Technologies (NGST) after the award of the Phase A/B contract. An updated model, based on PB1, is also being developed, which includes updated ion thruster performance and lifetime modeling

Two EPS designs were carried for TB2 because two ion thrusters and two power conversion systems were still under development. One design paired Brayton power conversion with the High Power Electric Propulsion ${ }^{9}$ (HiPEP) ion thruster and the other paired thermoelectric power conversion with the Nuclear Electric Xenon Ion System ${ }^{10}$ (NEXIS) ion thruster. Each carried individual power and $I_{S P}$ set points as well as voltage input type to the PP\&C system (AC for Brayton and DC for thermoelectric). TB2 also included a $4.5 \mathrm{~kW}_{\mathrm{e}} \mathrm{Hall}_{\text {ll }}$ thruster system to provide acceleration augmentation during the moon tour at Jupiter. The TB2 nominal parameters for each configuration are presented in Table 1.

Table 1. Summary of Key Design Parameters for Each of the EPS Baselines

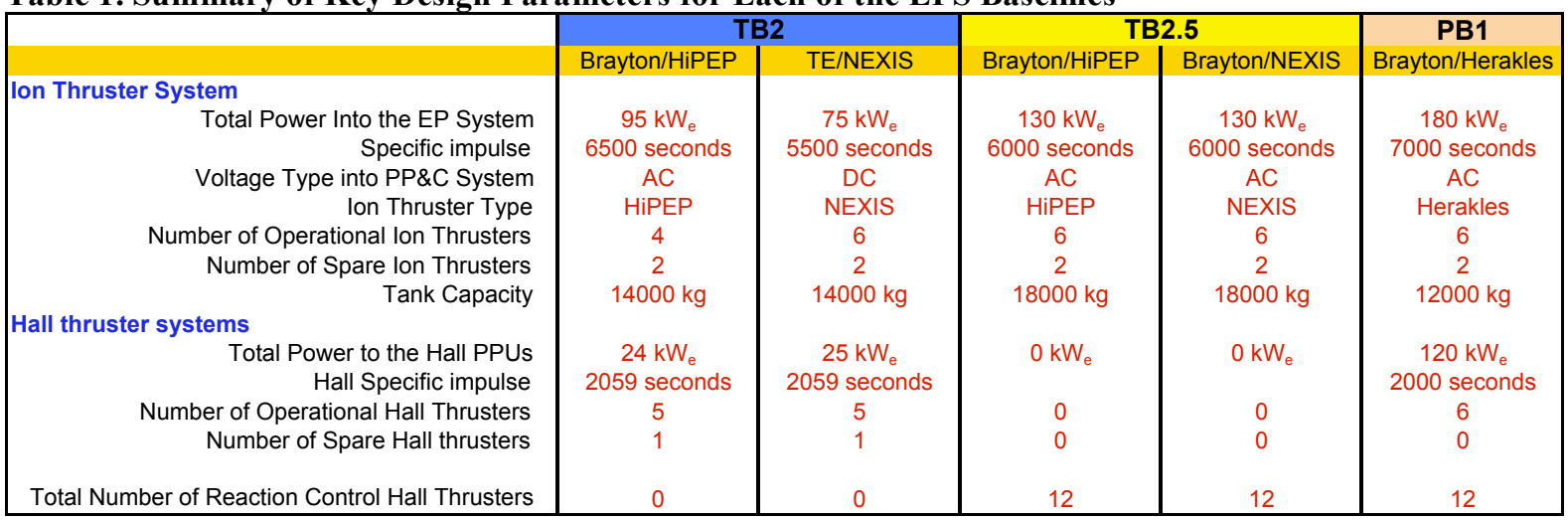


While Brayton power conversion was selected for TB2.5 and all following baselines, TB2.5 still included two EPS designs because the separate HiPEP and NEXIS thruster developments were still continuing. TB2.5 redirected the function of the $4.5 \mathrm{~kW}_{\mathrm{e}}$ Hall thruster system to perform attitude and reaction control functions, requiring a larger quantity of thrusters. Each of the TB2.5 EPS designs used the same defining parameters as shown in Table 1.

PB1 introduced the first unified design of the EPS. The HiPEP and NEXIS developments were combined and one ion thruster design was developed named Herakles ${ }^{11}$. This baseline also incorporated the team from NGST to help develop the baseline design. The EPS design for PB1 included a total of 26 electrostatic thrusters, 8 ion, 6 high power Hall thrusters, and 12 attitude/reaction control Hall thrusters ${ }^{12}$. The defining parameters for the PB1 EPS are shown in Table 1.

\section{Prometheus Electric Propulsion System Modeling}

The Prometheus EPS Model is required to estimate the mass of the EPS, performance information (efficiencies and quantities required of the different components), and in some cases dimensional information. Each of the EPS models estimates the mass, critical dimensions, and performance of the thruster systems as well as its associated support equipment (PP\&C system, propellant management system, and xenon tank). Depending on the EPS configuration for each of the Technical Baselines, the model also calculates the mass and performance of up to two Hall thruster systems, one for acceleration augmentation and the other for attitude and reaction control. Some of the models also include a small xenon cold gas reaction control system.

The models were designed to operate from a simple set of inputs, with the other pertinent parameters assumed based on the baseline designs. The ion thruster system was sized by providing input power, specific impulse, and total propellant throughput required, and based on calculations performed in the ion thruster model, the required quantity of thrusters was determined and used to calculate the mass of the system. The acceleration augmentation Hall thruster system was sized in much the same way as the ion system in the PB1 model, however for the TB2 model, the input power was determined by specifying the quantity of ion thrusters turned off to operate the Hall system, not the Hall system input power directly.

\section{A. Ion Thrusters}

Two ion thruster performance models were implemented over the course of the model development. The first, a purely physics-based model, was used during the early stages of development of the ion thruster system hardware (HiPEP and NEXIS). The second, incorporates ion thruster testing experience and was implemented as the ion thruster hardware design was finalized (Herakles). Each of these models requires power input to the thruster and required specific impulse in order to calculate the thruster operating point and performance. The thruster mass models were tied directly to mass estimates provided through the technology development efforts, whereas the performance estimates were somewhat unrelated to the technology development until the Herakles thruster design was developed.

\section{Physics-based Ion Thruster Model}

The purely physics based model is adapted from work by Wilbur ${ }^{13}$ and Brophy ${ }^{14}$ with the Current Best Estimate (CBE) of performance constants provided by the ion thruster technology development team (see Table 2) and updated periodically as the thruster development progressed. The equations, as presented in simplest form, require inputs of beam current $\left(J_{b}\right)$ and beam voltage $\left(V_{b}\right)$, and calculate the thruster performance with knowledge of the performance constants. These equations were solved algebraically to require thruster input power and specific impulse as inputs for the physics-based model.

Table 2. Performance Constants for the Physicsbased Ion Thruster Model

\begin{tabular}{|c|c|c|}
\hline Parameter & TB2 \& TB2.5 & PB1 \\
$\eta_{u}$ & 0.87 & 0.86 \\
$E_{b}$ & $170 \mathrm{~W} / \mathrm{A}$ & $210 \mathrm{~W} / \mathrm{A}$ \\
$f$ & 0.05 & 0.053 \\
$\eta_{\theta}$ & 0.98 & 0.98 \\
$P_{l}$ & $30 \mathrm{~W}$ & $0 \mathrm{~W}$ \\
$\mathrm{R}$ & 0.9 & 0.86 \\
$f_{a b}$ & 0.005 & 0.008 \\
\hline
\end{tabular}

Total thruster input power is calculated using the beam current and voltage as well as knowledge of the power losses of the thruster.

$$
P=J_{b} V_{b}+J_{b} E_{b}+J_{b} f_{a b} V_{b} / R+P_{l}
$$

The electrical efficiency of the thruster is the ratio of beam power to total power (Eq. 1). 


$$
\eta_{\varepsilon}=\frac{J_{b} V_{b}}{P}
$$

The doubles-to-singles correction factor is a function of the ratio of doubly charged to singly charged ions thruster constant.

$$
\eta_{\alpha}=\frac{1+f 0.5^{0.5}}{1+f}
$$

The input beam current and propellant utilization allow calculation of the thruster total mass flow rate.

$$
\dot{m}_{T}=\frac{m_{i} J_{b}}{e \eta_{u}}
$$

The thrust produced by each ion thruster is a function of both beam current and voltage.

$$
T=\left(\frac{2 m_{i}}{e}\right)^{1 / 2} \eta_{\alpha} \eta_{\theta} J_{b} V_{b}^{1 / 2}
$$

Specific impulse is calculated with knowledge of the thrust produced and total mass flow rate.

$$
I_{s p}=\frac{T}{g_{0} \dot{m}_{T}}
$$

Finally, the total thruster efficiency is calculated as a function of the above calculated and specified efficiencies.

$$
\eta=\eta_{\varepsilon} \eta_{u} \eta_{\alpha}{ }^{2} \eta_{\theta}^{2}
$$

Because sufficient modeling of the ion thruster life-limiting mechanisms had not been completed when this performance model was in use, a simple algorithm was used to determine the number of thrusters required at a given operating condition. First, the current density was limited to $2.2 \mathrm{~mA} / \mathrm{cm}^{2}$, which determined the minimum quantity of operating thrusters required at any operating point. (The current density is defined as the beam current $\left(J_{b}\right)$ divided by the active beam area of the thruster. The active beam area is the area of the ion thruster grids that contain orifices.) Second, the total propellant throughput per thruster was limited to $1.5 \mathrm{~kg} / \mathrm{cm}^{2}$ of active beam area. This throughput limit determined the quantity of thrusters required to process the total amount of propellant.

\section{Physics and Test-based Ion Thruster Model}

The most recent iteration of the ion thruster performance model includes some performance relationships based on test data from the NSTAR ${ }^{15}$ and $\mathrm{NEXT}^{16}$ thrusters as well as other precursor and lab hardware. This model uses many of the relationships presented in the last section as well as some of the

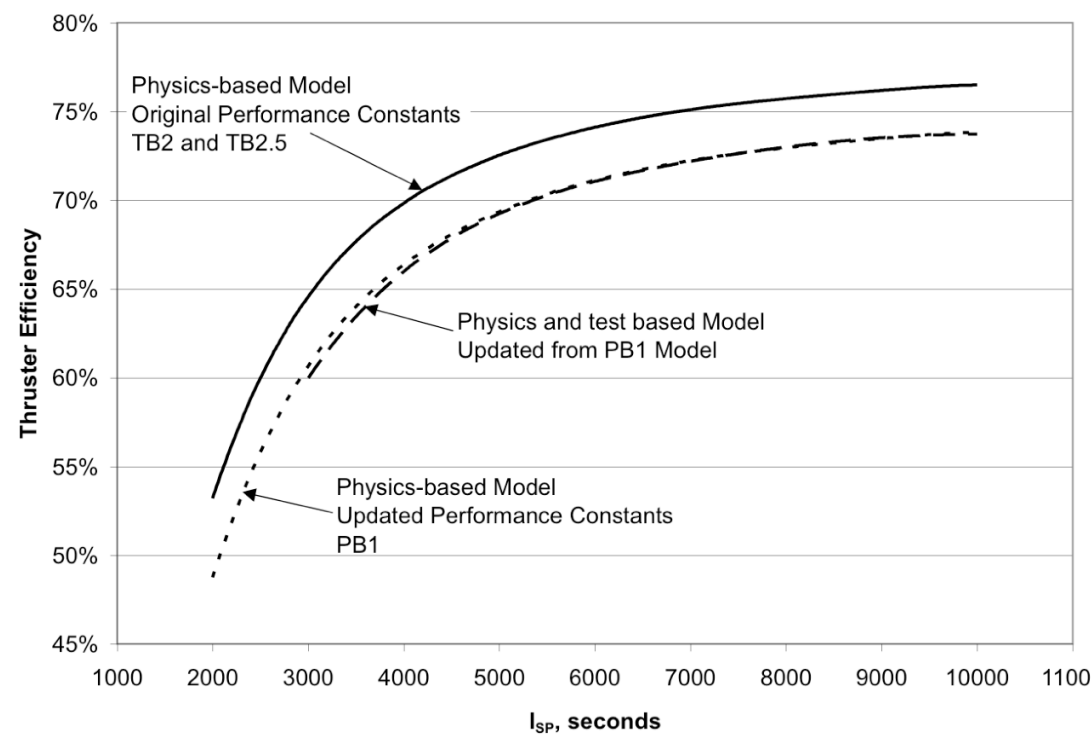

Figure 1. Performance Model Comparison 
same performance constants, but incorporates knowledge gained from ion thruster test experience. This inclusion of testing experience results in slightly lower thruster efficiency at the lower range of $I_{S P}$. A comparison of these models is presented in Figure 1.

\section{Ion Thruster Life Model}

The current version of the life estimation model was implemented to replace a more crude method of estimating the lifetime of ion thrusters. The earlier methodology involved placing a current density limit on the thrusters at which current density it was assumed that the thruster could survive long enough to process $1.5 \mathrm{~kg}$ of xenon per square centimeter of grid area. The result was a conservative estimate of how long an ion thruster might survive, but it failed to provide any insight into what mechanism would cause the eventual failure, nor did it provide a sense of the effect of changes to the system. The new life estimation model was developed as a tool for systems engineers to provide what the old model lacked.

The life estimation model provides rough estimates of thruster lifetime for systems engineering purposes and provides some insight into the ramifications of ion thruster operation at different conditions on thruster lifetime. However, it is not a detailed physical model. It is a collection of simple, independent fits to more detailed models and fits to empirical data. Four of the ion thruster failure modes modeled are discharge cathode failure due to barium depletion, discharge cathode failure due to keeper face erosion, electron back-streaming due to accelerator grid hole wall erosion, and accelerator grid failure due to pits-and-grooves erosion on the downstream surface. Other wear mechanisms have not been modeled, such as discharge cathode failure due to the formation of coatings on the emitting surface. The results the life model produces are obtained quickly with conservatism built-in and the interface is meant to be usable by non-experts. A separate life modeling and testing effort is developing detailed physics-based models that accurately predict lifetime and are validated by extensive experimental data ${ }^{17}$.

At the nominal operating point of a system power of $180 \mathrm{~kW}$ at a specific impulse of 7000 seconds, the life model shows that the thruster will fail at approximately $164 \mathrm{khrs}$. The life model is also used to calculate the quantity of thrusters needed for the mission. To determine the quantity of thrusters needed, the ion thruster model iterates the life model through the applicable operating points and chooses the minimum number of thrusters that are able to achieve the required lifetime.

\section{Ion Thruster Mass Model}

The ion thruster mass model was simply a result of the ion thruster technology development. The TB2 and TB2.5 mass models were based on the individual HiPEP and NEXIS ion thruster CBE mass, while the PB1 models used the CBE of the Herakles ion thruster mass. The Herakles design incorporated technologies developed for both HiPEP and NEXIS as well as lessons learned, and was not merely a down select to one thruster as the mass estimate may imply ${ }^{11}$. Ion thruster masses used in the system model for each technical baseline are tabulated in Table 3.

Table 3. Ion Thruster Masses for Each Baseline Design

\begin{tabular}{|r|c|c|c|}
\hline & TB2 & TB2.5 & PB1 \\
HiPEP ion thruster & $46.5 \mathrm{~kg}$ & $46.5 \mathrm{~kg}$ & \\
NEXIS ion thruster & $28.7 \mathrm{~kg}$ & $28.7 \mathrm{~kg}$ & \\
Herakles ion thruster & & & $49.5 \mathrm{~kg}$ \\
\hline
\end{tabular}

\section{B. Acceleration Augmentation Hall Thruster System}

An additional electric propulsion system model module was developed to allow the evaluation of augmenting the thrust provided by the ion thrusters to meet minimum acceleration requirements. Initially, this system was based on a $4.5 \mathrm{~kW}_{\mathrm{e}}$ Hall thruster system, but after TB2 the need was recognized for a higher power, newly designed Hall thruster system. This auxiliary system was based on Hall thruster technology that has demonstrated specific impulses in the range of $1400-2800$ seconds at power levels up to 50 kilowatts $^{18}$. Thruster performance was predicted based on an empirical relationship between thruster efficiency and specific impulse based on a range of experimental data ${ }^{18,19,20,21,22}$. The empirical curve fit had the following form:

$$
\eta=0.024 I_{s p}^{0.4}
$$

Thruster mass was estimated based on the thruster power and thruster size. A second empirical relationship between specific impulse and discharge voltage based on the experimental data shown in Figure 2 was used to determine the discharge voltage corresponding to the specific impulse of interest. This empirical relationship was: 


$$
V=0.013 I_{s p}^{1.35}
$$

The discharge current was then determined based on the desired thruster power and discharge voltage assuming thruster power could be estimated as the product of discharge voltage and discharge current. This assumption neglected the electrical power that is required to operate electromagnets, however, based on the prior experimental data this power is on the order of $1-2 \%$ of the total input power. As a result this error was considered acceptable. The thruster size was then determined based on propellant density requirements and the relationship between propellant mass flow rate and discharge current ${ }^{23}$. The result of these assumptions was a curve of Hall thruster specific mass as a function of specific impulse. This relationship, shown in Figure 3, was an attempt to capture the mass penalty associated with increased thruster size corresponding to low specific impulse operation resulting from a scaling methodology based on maintaining constant current and mass flow density. The state-of-the-art 10.1 kilogram $4.5 \mathrm{~kW}_{\mathrm{e}}$ BPT4000 Hall thruster specific mass ${ }^{24}$ compared favorably with the model of thruster specific mass versus specific impulse used for this investigation. The acceleration augmentation Hall thruster masses at each baseline design are

Table 4. Acceleration Augmentation Hall Thruster Parameters for Each Baseline Design

\begin{tabular}{|r|c|c|c|}
\hline & TB2 & TB2.5 & PB1 \\
Input Power & $4.5 \mathrm{~kW}$ & & $20.0 \mathrm{~kW}$ \\
Hall Thruster Mass & $12.3 \mathrm{~kg}$ & & $41.2 \mathrm{~kg}$ \\
\hline
\end{tabular}
shown in Table 4.

Because this system was used to augment the acceleration of the ion thruster system, joint operation of ion and Hall thrusters was assumed. This secondary system, composed of both ion and Hall thrusters, provided sufficient acceleration to maintain stable orbits at Jupiter and its moons. Therefore, calculation of the performance of the combined system was required. The combined performance was calculated by summing the thrust and mass flow rate of the two systems and then solving for specific impulse and efficiency.

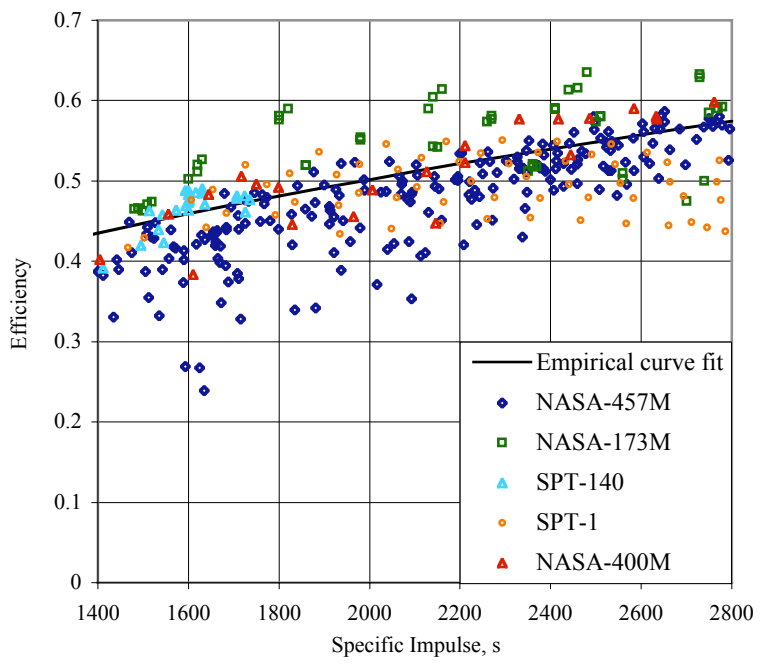

Figure 2. Hall thruster performance data and empirical fit

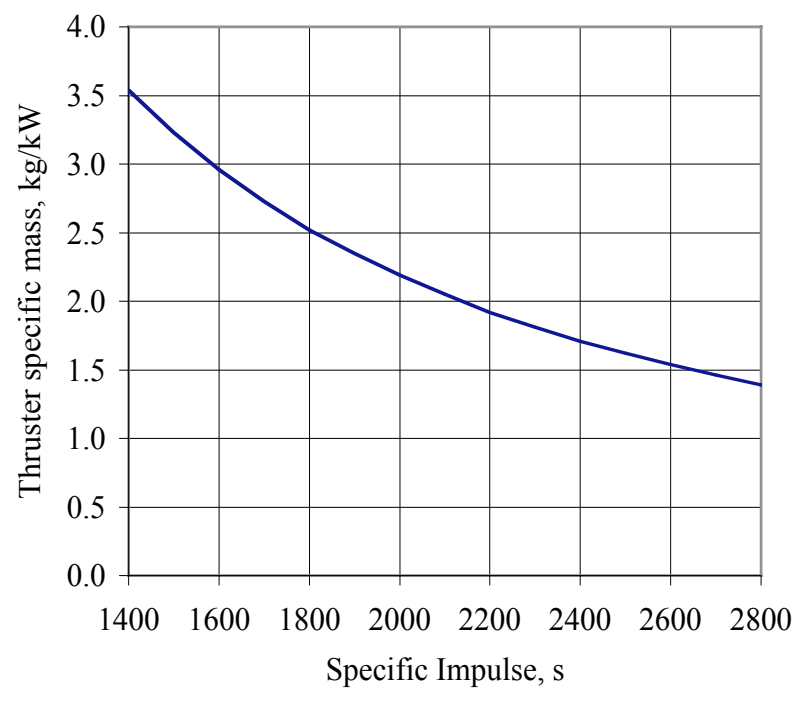

Figure 3. Hall thruster specific mass

\section{Attitude and Reaction Control Hall Thruster System}

TB2.5 and PB1 utilized a Hall thruster system to perform attitude and reaction control functions for the spacecraft. The TB2.5 model utilized a reconfigured $4.5 \mathrm{~kW}_{\mathrm{e}}$ Hall thruster system to perform these functions. Specifically, the thruster quantity was increased to 12 thrusters crossstrapped to six PP\&C units. The PB1 model introduced a smaller Hall thruster system, also composed of 12

Table 5. Attitude and Reaction Control System Parameters for Each Baseline Design

\begin{tabular}{|r|c|c|c|}
\hline & TB2 & TB2.5 & PB1 \\
Quantity of Thrusters & & 12 & 12 \\
Thruster Input Power & & $4.5 \mathrm{~kW}$ & $0.7 \mathrm{~kW}$ \\
Hall Thruster System Mass & & $274 \mathrm{~kg}$ & $83 \mathrm{~kg}$ \\
\hline
\end{tabular}


thrusters cross-strapped to $6 \mathrm{PP} \& \mathrm{C}$ units, with $700 \mathrm{~W}_{\mathrm{e}}$ thrusters. The attitude and reaction control Hall thruster system parameters at each technical baseline are presented in Table 5.

\section{Power Processing and Control System}

The Power Processing and Control (PP\&C) System model is a direct representation of the PP\&C technology development ${ }^{25}$. Initially, two PP\&C systems were designed to accept AC and DC input from the Brayton and thermoelectric power conversion systems, respectively. The DC PP\&C system was scaled from the NEXT powerprocessing unit ${ }^{26}$ while the AC PP\&C system's discharge and ancillary supplies (cathode heaters and keepers, accelerator supply, controller, etc.) were also scaled from the NEXT power-processing unit and mated with a newly designed transformer-rectifier module to provide main beam power. PP\&C system efficiencies were estimated based on the current state of the technology development for each baseline and for each input voltage type and assumed constant over the range of input power levels (see Table 6). PP\&C unit dimensions were also estimated to allow calculation of radiation shielding mass. Because calculation of radiation shielding mass was done externally to the EPS model and the PP\&C unit dimensions have no impact on the EPS design, neither the PP\&C unit dimensions nor the radiation shielding mass are discussed

Table 6. Ion PP\&C System Parameters for Each Baseline Design
\begin{tabular}{|r|c|c|c|}
\hline & TB2 & TB2.5 & PB1 \\
AC PP\&C Unit & & & \\
PP\&C Unit Input Power & $23.8 \mathrm{~kW}$ & $32.5 \mathrm{~kW}$ & $30.0 \mathrm{~kW}$ \\
Efficiency & $96.5 \%$ & $96.5 \%$ & $95.0 \%$ \\
AC Frequency & $1000 \mathrm{~Hz}$ & $1000 \mathrm{~Hz}$ & $2200 \mathrm{~Hz}$ \\
$f(\omega)$ & 2.92 & 2.92 & 1.47 \\
PP\&C Unit Mass & $57.9 \mathrm{~kg}$ & $72.4 \mathrm{~kg}$ & $50.3 \mathrm{~kg}$ \\
DC PP\&C Unit & & & \\
PP\&C Unit Input Power & $12.5 \mathrm{~kW}$ & & \\
Efficiency & $94.0 \%$ & & \\
PP\&C Unit Mass & $37.6 \mathrm{~kg}$ & & \\
\hline
\end{tabular}
herein.

The PP\&C system mass model evolved with each technical baseline as the technology development progressed. The DC PP\&C model implemented for TB2 combined component module masses from the NEXT powerprocessing unit. These modules were either scaled up in mass, or extra components were added to accommodate higher power levels. The AC PP\&C model evolved with each baseline design as the PP\&C system technology was developed. Each AC PP\&C model utilized a simple power function (Eq. 8) to size the beam module transformers with different coefficients that were dependent on the frequency of the input power supplied.

$$
m_{\text {Beam }}=f(\omega) P_{P P \& C} 0.87
$$

The AC frequency coefficients $(f(\omega))$ are presented in Table 4 . The masses of the other PP\&C system components were modeled differently for each of the technical baselines. For TB2 and TB2.5 the discharge and ancillary power supplies were modeled as a constant $12 \mathrm{~kg}$ mass. The discharge power supply was modeled as

$$
m_{\text {Disch arge }}=0.105 J_{d}
$$

for PB1 with a constant $17 \mathrm{~kg}$ carried for the ancillary supply mass. The PP\&C unit masses at each of the technical baselines are also presented in Table 6 .

The Hall thruster PP\&C units were modeled in much the same way as the ion thruster PP\&C units. The TB2 and TB2.5 Hall systems, although performing different functions, were $4.5 \mathrm{~kW}_{\mathrm{e}}$ Hall thruster systems. This Hall system was estimated to have a PP\&C system design mass of $6 \mathrm{~kg}$ in the direct-drive configuration of TB2 and $12.6 \mathrm{~kg}$ for TB2.5, both with AC input. The PB1 model used the transformer mass estimate (Eq. 12) and to it added $9 \mathrm{~kg}$ of mass for ancillary supplies for the acceleration augmentation Hall system and $4 \mathrm{~kg}$ for the attitude and reaction control system. System parameters for the Hall thruster PP\&C systems at each baseline design are presented in Table 7.

Table 7. Hall PP\&C System Parameters for Each Baseline Design

\begin{tabular}{|r|c|c|c|c|}
\hline & \multicolumn{2}{|c|}{ TB2 } & TB2.5 & $\begin{array}{c}\text { PB1 } \\
\text { Acrakles }\end{array}$ \\
PP\&C Unit Input Power & Brayton/HiPEP & TE/NEXIS & HiPEP or NEXIS & \\
Efficiency & $4.7 \mathrm{~kW}$ & & & \\
PP\&C Unit Mass & $96.0 \%$ & $9.7 \mathrm{~kW}$ & & $20.0 \mathrm{~kW}_{\mathrm{e}}$ \\
Attitude \& Reacton Control & $6.0 \mathrm{~kg}$ & $4.2 \mathrm{~kg}$ & & $94.0 \%$ \\
PP\&C Unit Input Power & & & & $28.9 \mathrm{~kg}$ \\
Efficiency & & & $4.7 \mathrm{~kW}_{\mathrm{e}}$ & $0.7 \mathrm{~kW}$ \\
PP\&C Unit Mass & & & $96.5 \%$ & $94.0 \%$ \\
\hline
\end{tabular}




\section{E. Propellant Management System}

The Propellant Management System mass model was comprised of three parts; the isolation and pressure regulation module, the xenon flow control assembly, and the xenon recovery system. The isolation and pressure regulation module isolates the tank from the downstream components and regulates the pressure of the xenon from the tank to a lower pressure useable by the xenon flow control assemblies. The xenon flow control assemblies receive the regulated xenon from the isolation and pressure regulation module and splits and controls the flow to the two cathodes and the main discharge of the ion thrusters. The xenon recovery system allows xenon to be extracted from the tank once the tank pressure reaches a pressure too low for normal propellant management system operation. One isolation and pressure regulation module and one xenon recovery system is needed, as well as one xenon flow controller per thruster. This model was based on the current design of the propellant management system at the time of the technical baselines. The propellant management system masses at each of the technical baselines are presented in Table 8. The changes in masses between technical baselines were due to updates to the CBE mass as the propellant management system design evolved.

\begin{tabular}{|c|c|c|c|c|}
\hline & \multicolumn{2}{|c|}{ TB2 } & \multirow{2}{*}{\begin{tabular}{|c|} 
TB2.5 \\
HiPEP or NEXIS
\end{tabular}} & \multirow{2}{*}{$\begin{array}{c}\text { PB1 } \\
\text { Herakles }\end{array}$} \\
\hline & Brayton/HiPEP & TE/NEXIS & & \\
\hline \multicolumn{5}{|l|}{ Shared Hardware } \\
\hline Isolation and Pressure Regulation Module & $10.2 \mathrm{~kg}$ & $10.2 \mathrm{~kg}$ & $10.2 \mathrm{~kg}$ & $16.4 \mathrm{~kg}$ \\
\hline Xenon Recovery System & $23.1 \mathrm{~kg}$ & $23.1 \mathrm{~kg}$ & $23.1 \mathrm{~kg}$ & $23.0 \mathrm{~kg}$ \\
\hline \multicolumn{5}{|l|}{ Ion Thruster Hardware } \\
\hline Xenon Flow Control Assembly & $3.9 \mathrm{~kg}$ & $3.9 \mathrm{~kg}$ & $3.8 \mathrm{~kg}$ & $5.6 \mathrm{~kg}$ \\
\hline Tubing, fittings, structure, etc. & $10.3 \mathrm{~kg}$ & $10.3 \mathrm{~kg}$ & $10.3 \mathrm{~kg}$ & $6.3 \mathrm{~kg}$ \\
\hline Quantity of Ion Thrusters & 6 & 8 & 6 & 8 \\
\hline \multicolumn{5}{|l|}{ Acceleration Augmentation Hall Hardware } \\
\hline Xenon Flow Control Assembly & $0.7 \mathrm{~kg}$ & $0.7 \mathrm{~kg}$ & & $2.7 \mathrm{~kg}$ \\
\hline Tubing, fittings, structure, etc. & $0.0 \mathrm{~kg}$ & $0.0 \mathrm{~kg}$ & & $1.7 \mathrm{~kg}$ \\
\hline Quantity of Large Hall Thrusters & 6 & 6 & & 6 \\
\hline \multicolumn{5}{|l|}{ ACS Hall Thruster Hardware } \\
\hline Xenon Flow Control Assembly & & & $0.7 \mathrm{~kg}$ & $2.1 \mathrm{~kg}$ \\
\hline Tubing, fittings, structure, etc. & & & $0.2 \mathrm{~kg}$ & $0.4 \mathrm{~kg}$ \\
\hline Quantity of Large Hall Thrusters & & & 12 & 12 \\
\hline Total & $123.0 \mathrm{~kg}$ & $151.4 \mathrm{~kg}$ & $129.3 \mathrm{~kg}$ & $192.0 \mathrm{~kg}$ \\
\hline
\end{tabular}

\section{F. Xenon Tank}

Two different xenon tank models were implemented in the EPS model. The first was based on point designs at the time of each technical baseline, with any capacity deviation completed by scaling the tank mass linearly with propellant capacity mass. The second xenon tank model is a higher fidelity model based on previous tank design experience and the known properties of xenon at the required state. Both models assumed that the xenon was stored as a supercritical fluid. TB2 and TB2.5 utilized the simple linearly scaled tank, while PB1 used the higher fidelity tank model. The xenon tank masses are presented in Table 9.

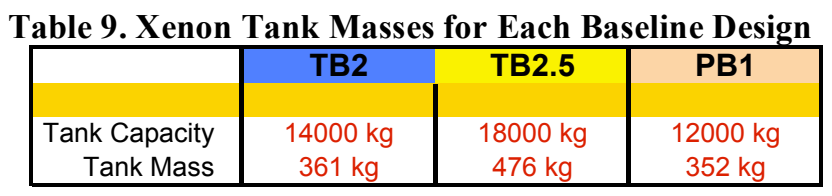

\section{G. Xenon Reaction Control System}

A small xenon cold gas thruster system was included in TB2 and TB2.5 to cancel any perturbations due to the launch vehicle separation before power was available for the EPS. This system was designed using currently available commercial components. The $I_{S P}$ of this system was assumed to be 29 seconds, and a constant mass of 5.1 $\mathrm{kg}$ was included in the EPS model for this system.

\section{Electric Propulsion System Model Performance}

The performance of the EPS models developed for each of the technical baselines provides insight into both the baseline designs and the evolution of the EPS model. The four models, TB2, TB2.5, P1, and updated P1, were run at input power levels between $50 \mathrm{~kW}_{\mathrm{e}}$ and $300 \mathrm{~kW}_{\mathrm{e}}$ at a constant $I_{S P}$ of 7000 seconds (note that only the Brayton/HiPEP configuration was used for the TB2 model data). The total EPS mass output from each model, as well as marks denoting the three technical baselines can be seen in Figure 4. Mass differences between models are primarily due to EPS configuration changes (i.e. addition of Hall thruster systems). The discrete steps in the data occur when the EPS model increments the quantity of thrusters, either ion or Hall, to process the total amount of power input to the EPS.

The mass breakdown of each EPS model output provides further understanding of the performance of the models. Figure 5 shows plots of the mass breakdown of each EPS model. Also detailed are the discrete jumps in the data where the quantity of ion thruster changes. Examination of the data labeled "Hall Mass," also reveals discrete jumps where the quantity of Hall thrusters changes. The Hall thruster system mass for the TB2 model (shown in 
Figure 5a) is the result of setting the input power of the Hall thrusters as the power gained by shutting down one ion thruster at all input power levels, whereas the Hall thruster system mass for the two PB1 models (shown in Figure 5c and d) is the result of approximately maintaining the ratio of Hall system input power to total EPS input power.

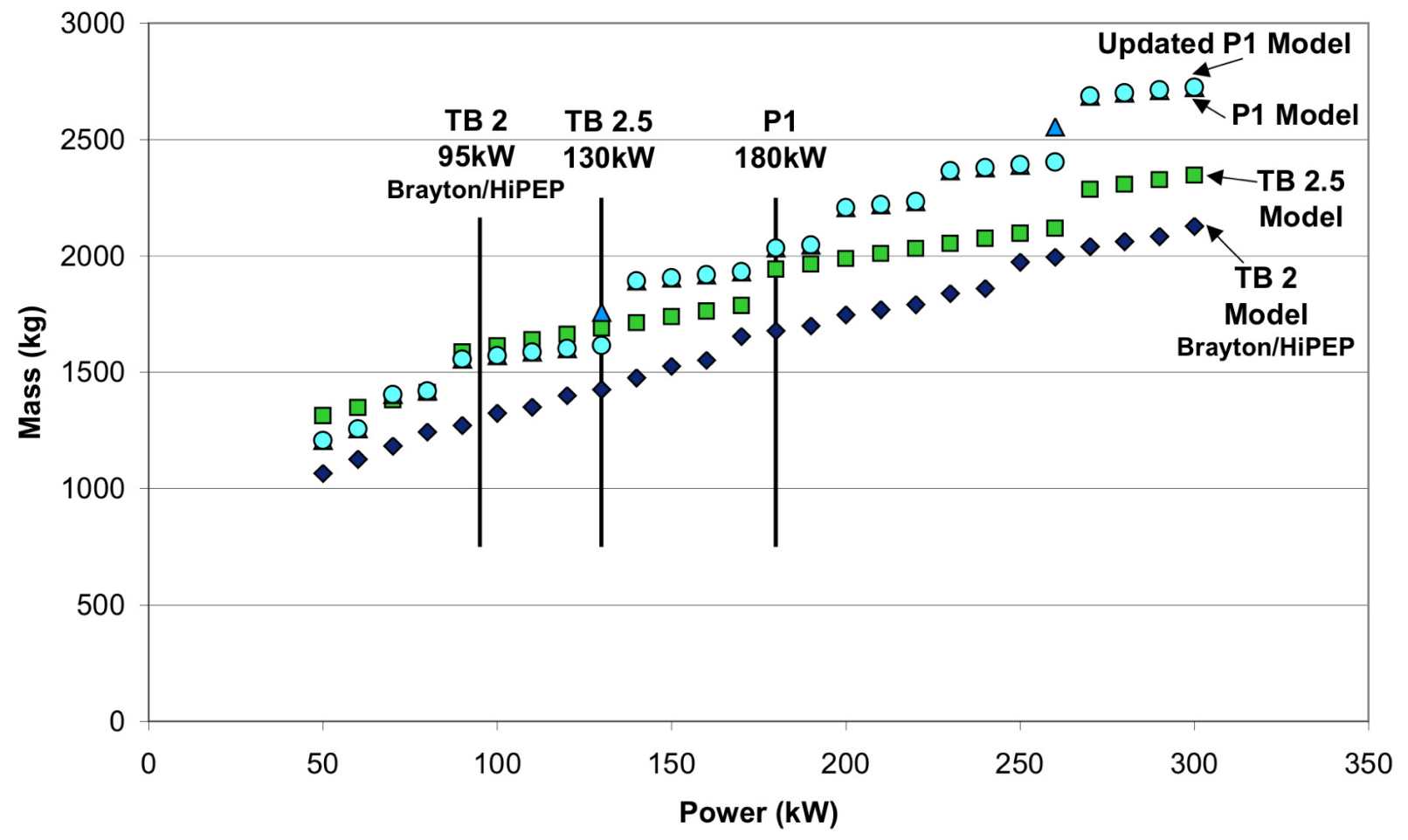

Figure 4. Mass Performance of the EPS Model Iterations

\section{Future Plans for the Electric Propulsion System Model}

Future modifications to the EPS model fall into two categories; modifications based on technology development and capability enhancements. Modifications based on technology development include implementation of any design changes throughout the development of the EPS hardware, modifying the performance assumptions as performance tests of the EPS hardware are completed, and updating life model assumptions to reflect the wear mechanisms examined through long duration hardware tests. Many performance and life tests are planned as part of the Prometheus Project, which may result in design modifications of EPS hardware. These design modifications must be reflected in the EPS model in order to accurately represent the EPS in trades performed with the Prometheus system model. Capability enhancements that may be implemented mainly add flexibility to the EPS model and make it a more general tool, not necessarily tailored to the proposed JIMO mission. These capability enhancements could include several thruster modules representing different technologies that can be switched out easily depending on the mission requirements, a second tank and propellant management system model for cryogenic storage of propellant, or a higher fidelity approach to tracking uncertainties in the performance of the thrusters over the length of the mission. 

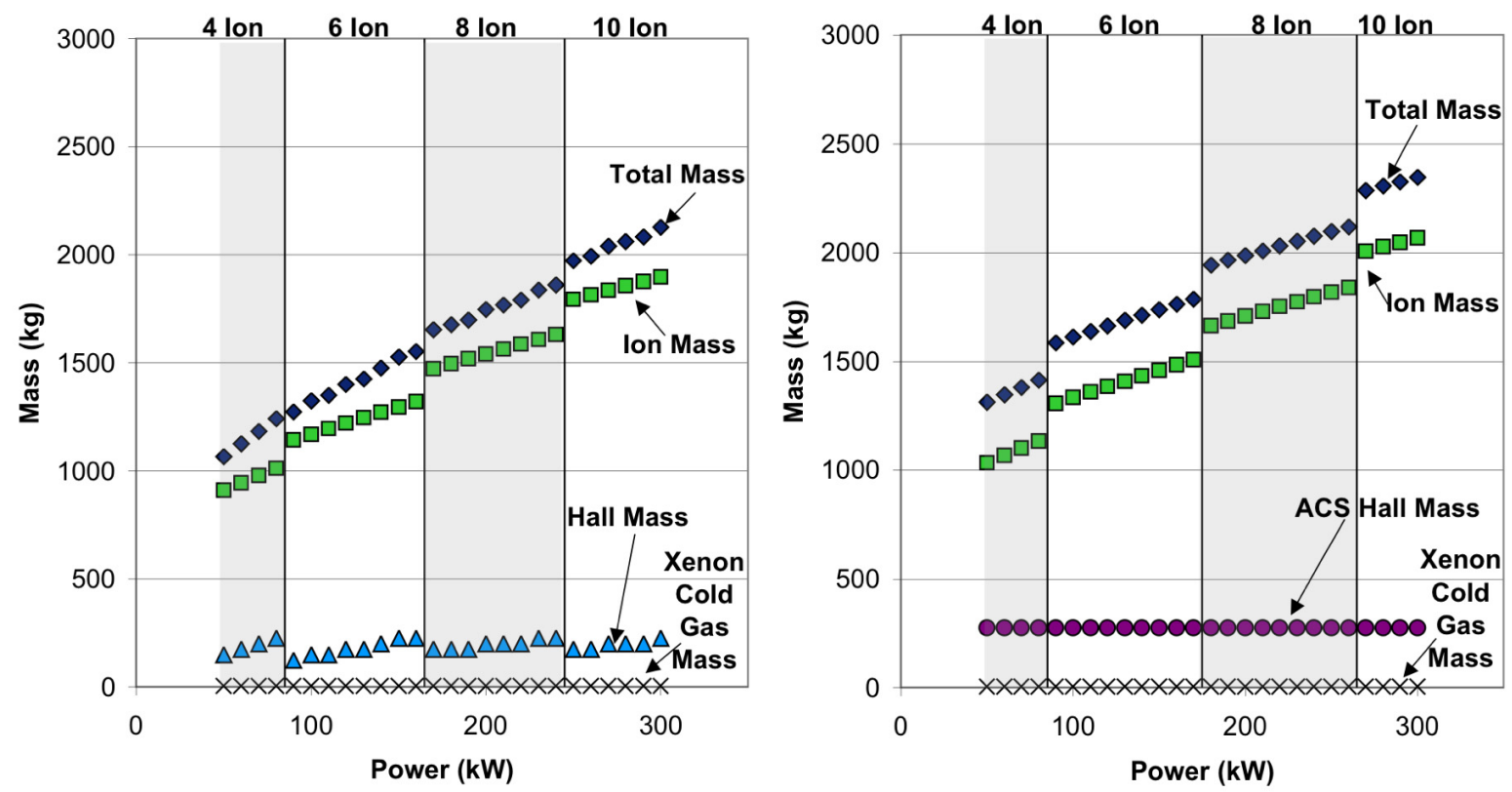

a) TB2 Model, Brayton/HiPEP Config.

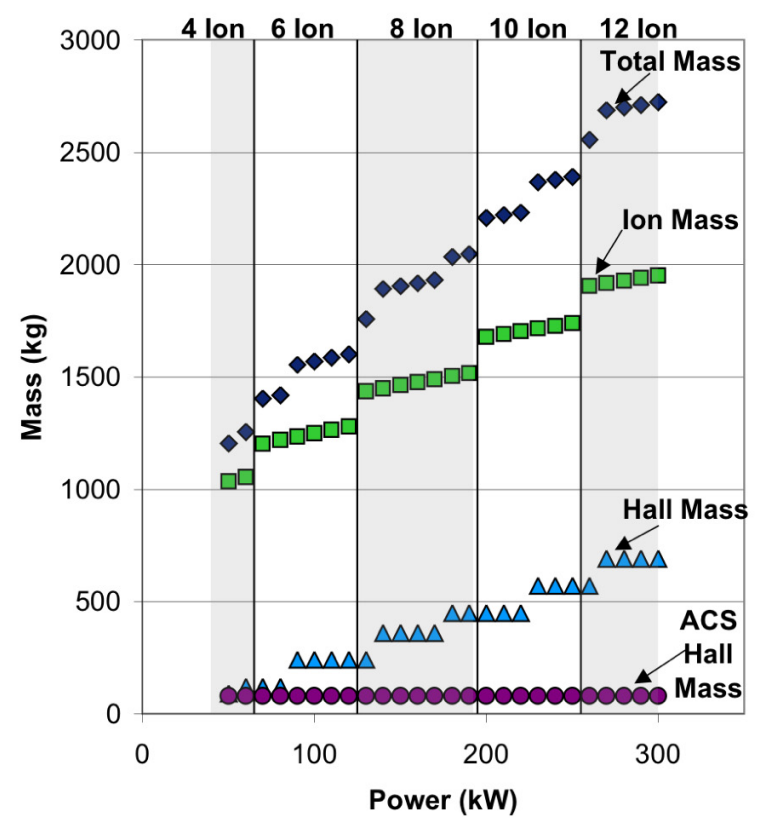

c) PB1 Model

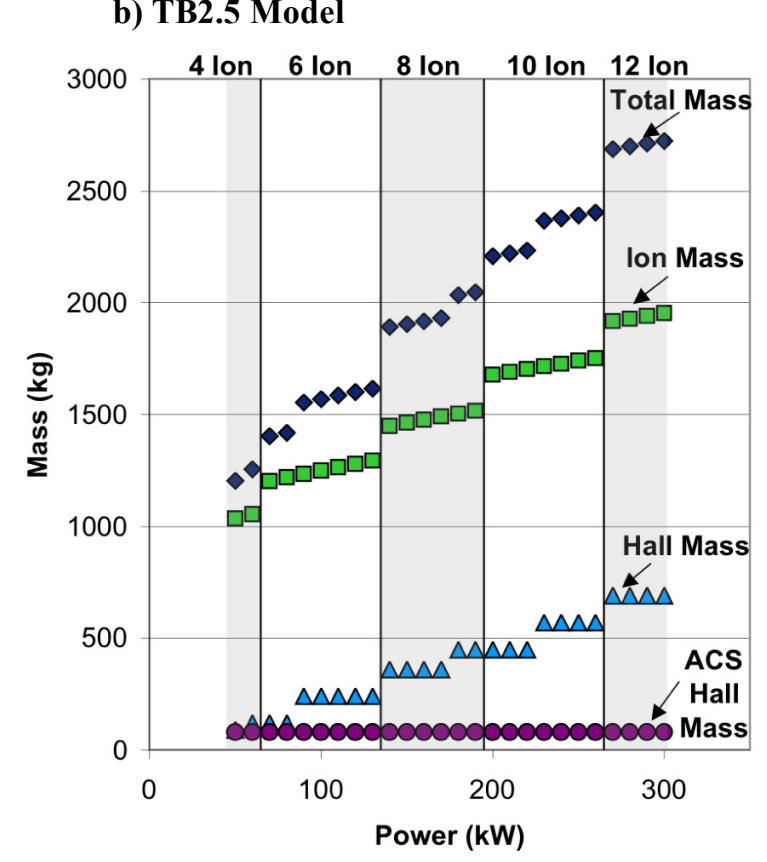

d) Updated PB1 Model

Figure 5. Mass Performance Breakdown of Each EPS Model

\section{References}

1 Taylor, R., Kremer, B., Schmidt, G., "Prometheus: Energy for Exploration," IAC-04-R.4-S.7.01, 55 ${ }^{\text {th }}$ International Astronautical Congress, Vancouver, B.C., October, 2004.

${ }^{2}$ Quadrelli, M. B., Mettler, E., Langmaier, J. K., "Dynamics and Controls of a Conceptual Jovian Moon Tour Spacecraft," AIAA-2004-4866, AIAA/AAS Astrodynamics Specialist Conference and Exhibit, Providence, RI, August 2004.

${ }^{3}$ Weiler, E. J., 2003, "Statement of Dr. Edward J. Weiler, Associate Administrator, Office of Space Science, National Aeronautics and Space Administration," Before the U.S. Senate Committee on Commerce, Science, and Transportation: Subcommittee on Science, Technology, and Space, Hearing on Space Propulsion, 108th Congress, 1st Session, June 3, 2003. (Available from the internet at: http://legislative.nasa.gov/hearings/weiler6-3.pdf) 
${ }^{4}$ Barrett, M. J., "Performance Expectations of Closed-Brayton-Cycle Heat Exchangers in 100-kWe Nuclear Space Power Systems," AIAA-2003-5956, $1^{\text {st }}$ International Energy Conversion Engineering Conference, Portsmouth, VA, August 2003.

${ }^{5}$ Mason, L. S., “A Power Conversion Concept for the Jupiter Icy Moons Orbiter,” AIAA-2003-6007, $1{ }^{\text {st }}$ International Energy Conversion Engineering Conference, Portsmouth, VA, August 2003.

${ }^{6}$ Oleson, S. R., "Electric Propulsion for Project Prometheus' Jupiter Icy Moons Orbiter," AIAA-2004-5908, Space 2004 Conference and Exhibit, San Diego, CA, September 2004

${ }^{7}$ Noca, M., Girerd, A., Weglian, J., Falck, R., Fiehler, D., Kang, S., Miyake, R., Beech, G., Tidwell, P., Carr, G., Hack, K., “Jupiter Icy Moons Orbiter System Model v3.0 Description," Prometheus Project Document Number 982-R20375, December 2004

${ }^{8}$ Noca, M. A., Hack, K. J., "Results of the JIMO Follow-on Destinations Parametric Studies," Proceedings of the Space Technology and Applications International Forum 2005, edited by M. El-Genk, Vol. 746, American Institute of Physics, Albuquerque, NM, 2005

9 Elliott, F. W., Foster, J. E., Patterson, M. J., “An Overview of the High Power Electric Propulsion (HiPEP) Project,” AIAA2004-3453, 40 ${ }^{\text {th }}$ AIAA/ASME/SAE/ASEE Joint Propulsion Conference and Exhibit, Fort Lauderdale, FL, July 2004.

${ }^{10}$ Randolph, T. M., Polk, J. E., "An Overview of the Nuclear Electric Xenon Ion System (NEXIS) Activity," AIAA-20043450, 40 ${ }^{\text {th }}$ AIAA/ASME/SAE/ASEE Joint Propulsion Conference and Exhibit, Fort Lauderdale, FL, July 2004.

${ }^{11}$ Patterson, M. J., Elliott, F., Malone, S., Soulas, G., Goebel, D., Katz, I., "Herakles Thruster Development for the Prometheus JIMO Mission," AIAA-2005-3890, $41^{\text {st }}$ AIAA/ASME/SAE/ASEE Joint Propulsion Conference \& Exhibit, Tucson, AZ, July 2005.

${ }^{12}$ Randolph, T. M., Dougherty, R. C., Oleson, S. R., Fiehler, D. I., Dipprey, N., "The Prometheus 1 Spacecraft Preliminary Electric Propulsion System Design," AIAA-2005-3889, $41^{\text {st }}$ AIAA/ASME/SAE/ASEE Joint Propulsion Conference and Exhibit, Tucson, AZ, July 2005.

${ }^{13}$ Wilbur, P. J., "Ion Propulsion, Course Notes of Professor Paul Wilbur," Colorado State University.

${ }^{14}$ Brophy, J. R. Wilbur, P. J., "Simple Performance Model for Ring and Line Cusp Ion Thrusters," AIAA Journal, Vol. 23, No. 11, 1985, pp. 1731-1736.

${ }^{15}$ Polk, J.E., Kakuda, R. Y., Anderson, J. R., Brophy, J. R., Rawlin, V. K., Patterson, M. J., Sovey, J., Hamley, J., "Performance of the NSTAR Ion Propulsion System on the Deep Space One Mission," AIAA-2001-0965, 39 $9^{\text {th }}$ AIAA Aerospace Sciences Meeting \& Exhibit, Reno, NV, January 2001.

${ }^{16}$ Soulas, G. C., Domonkos, M. T., Patterson, M. J., "Performance Evaluation of the NEXT Ion Engine," AIAA-2003-5278, $39^{\text {th }}$ AIAA/ASME/SAE/ASEE Joint Propulsion Conference and Exhibit, Huntsville, AL, July 2003.

17 Katz, I., Mikellides, I., Anderson J., Goebel, D., Wirz, R., "Ion Thruster Life Models." AIAA-2005-4256, 41 ${ }^{\text {st }}$ AIAA/ASME/SAE/ASEE Joint Propulsion Conference \& Exhibit, Tucson, AZ, July 2005.

18 Manzella, D., Jankovsky, R., and Hofer, R., "Laboratory Model 50 kW Hall Thruster," AIAA-2002-3676, 38 AIAA/ASME/SAE/ASEE Joint Propulsion Conference and Exhibit, Indianapolis, IN, July 2002.

${ }^{19}$ Hofer, R., "Development and Characterization of High-Efficiency, High-Specific Impulse Xenon Hall Thrusters," Doctoral Thesis, University of Michigan, Department of Aerospace Engineering, 2004.

${ }^{20}$ Manzella, D., Hamley, J., Miller, J., Clauss, C., Kozubsky, K., and Gnizdor, R., "Operational Characteristics of the SPT140 Hall Thruster," AIAA-1997-2919, 33 ${ }^{\text {rd }}$ AIAA/ASME/SAE/ASEE Joint Propulsion Conference and Exhibit, Seattle, WA, July 1997.

21 Manzella, D., Jacobson, D., and Jankovsky, R., "High Voltage SPT Performance," AIAA-2001-3774, 37"th AIAA/ASME/SAE/ASEE Joint Propulsion Conference and Exhibit, Salt Lake City, UT, July 2001.

${ }^{22}$ Peterson, P., Jacobson. D., Manzella, D., and John, J., "The Performance and Wear Characterization of a High-Power High-Isp NASA Hall Thruster,” AIAA-2005-4243, 41 ${ }^{\text {st }}$ AIAA Joint Propulsion Conference, Tuscon, AZ, July 2005.

${ }^{23}$ Manzella, D., Jacobson, D., Peterson, P., Hofer, R., "Scaling Hall Thrusters to High Power," 52 ${ }^{\text {nd }}$ JANNAF Propulsion Meeting, Las Vegas, NV, May 2004.

${ }^{24}$ De Grys, K. et. al, "4.5 kW Hall Thruster System Qualification Status," 40 ${ }^{\text {th }}$ AIAA Joint Propulsion Conference, AIAA2004-3603, 40 ${ }^{\text {th }}$ AIAA/ASME/SAE/ASEE Joint Propulsion Conference and Exhibit, Fort Lauderdale, Fl, July 2004.

${ }^{25}$ Gerber, S., "Status on a Power Processing Unit for the Prometheus 1 Electric Propulsion System," AIAA-2005-3895, to be presented at the $41^{\text {st }}$ AIAA/ASME/SAE/ASEE Joint Propulsion Conference and Exhibit, Tucson, AZ, July 2005.

${ }^{26}$ Todd, P., Wiseman, S., Martinelli, R., Pinero, L., "Status of the NEXT 7 kW Power Processing Unit," AIAA-2005-3868, to be presented at the $41^{\text {st }}$ AIAA/ASME/SAE/ASEE Joint Propulsion Conference and Exhibit, Tucson, AZ, July 2005. 


\begin{tabular}{|c|c|c|}
\hline \multicolumn{2}{|c|}{ REPORT DOCUMENTATION PAGE } & $\begin{array}{l}\text { Form Approved } \\
\text { OMB No. 0704-0188 }\end{array}$ \\
\hline \multicolumn{3}{|c|}{$\begin{array}{l}\text { Public reporting burden for this collection of information is estimated to average } 1 \text { hour per response, including the time for reviewing instructions, searching existing data sources } \\
\text { gathering and maintaining the data needed, and completing and reviewing the collection of information. Send comments regarding this burden estimate or any other aspect of thi } \\
\text { collection of information, including suggestions for reducing this burden, to Washington Headquarters Services, Directorate for Information Operations and Reports, } 1215 \text { Jefferson } \\
\text { Davis Highway, Suite 1204, Arlington, VA 22202-4302, and to the Office of Management and Budget, Paperwork Reduction Project (0704-0188), Washington, DC 20503. }\end{array}$} \\
\hline 1. AGENCY USE ONLY (Leave blank) & \begin{tabular}{|} 
2. REPORT DATE \\
September 2005
\end{tabular} & $\begin{array}{l}\text { ID DATES COVERED } \\
\text { echnical Memorandum }\end{array}$ \\
\hline \multicolumn{2}{|c|}{ Electric Propulsion System Modeling for the Proposed Prometheus 1 Mission } & 5. FUNDING NUMBERS \\
\hline $\begin{array}{l}\text { 6. AUTHOR(S) } \\
\text { Douglas Fiehler, Ryan Doug }\end{array}$ & Douglas Fiehler, Ryan Dougherty, and David Manzella & WBS-22-982-10-41 \\
\hline $\begin{array}{l}\text { 9. SPONSORING/MONITORING AGEI } \\
\text { National Aeronautics and Sp } \\
\text { Washington, DC } 20546-00\end{array}$ & $\begin{array}{l}\text { NAME(S) AND ADDRESS(ES) } \\
\text { Administration }\end{array}$ & $\begin{array}{l}\text { 10. SPONSORING/MONITORING } \\
\text { AGENCY REPORT NUMBER } \\
\text { NASA TM-2005-213892 } \\
\text { AIAA-2005-3891 }\end{array}$ \\
\hline
\end{tabular}

\section{SUPPLEMENTARY NOTES}

Prepared for the 41st Joint Propulsion Conference and Exhibit cosponsored by the AIAA, ASME, SAE, and ASEE, Tucson, Arizona, July 10-13, 2005. Douglas Fiehler, QSS Group, Inc., 21000 Brookpark Road, Cleveland, Ohio 44135; Ryan Dougherty, NASA Jet Propulsion Laboratory; and David Manzella, NASA Glenn Research Center. Responsible person, Douglas Fiehler, organization code RPP, 216-433-2584.

\begin{tabular}{|l|l|l|l|l|}
\hline 12a. DISTRIBUTION/AVAILABILITY STATEMENT & DISTRIBUTION CODE
\end{tabular}

Unclassified - Unlimited

Subject Category: 20

Available electronically at http://gltrs.grc.nasa.gov

This publication is available from the NASA Center for AeroSpace Information, 301-621-0390.

13. ABSTRACT (Maximum 200 words)

The proposed Prometheus 1 spacecraft would utilize nuclear electric propulsion to propel the spacecraft to its ultimate destination where it would perform its primary mission. As part of the Prometheus 1 Phase A studies, system models were developed for each of the spacecraft subsystems that were integrated into one overarching system model. The Electric Propulsion System (EPS) model was developed using data from the Prometheus 1 electric propulsion technology development efforts. This EPS model was then used to provide both performance and mass information to the Prometheus 1 system model for total system trades. Development of the EPS model is described, detailing both the performance calculations as well as its evolution over the course of Phase A through three technical baselines. Model outputs are also presented, detailing the performance of the model and its direct relationship to the Prometheus 1 technology development efforts. These EP system model outputs are also analyzed chronologically showing the response of the model development to the four technical baselines during Prometheus 1 Phase A.

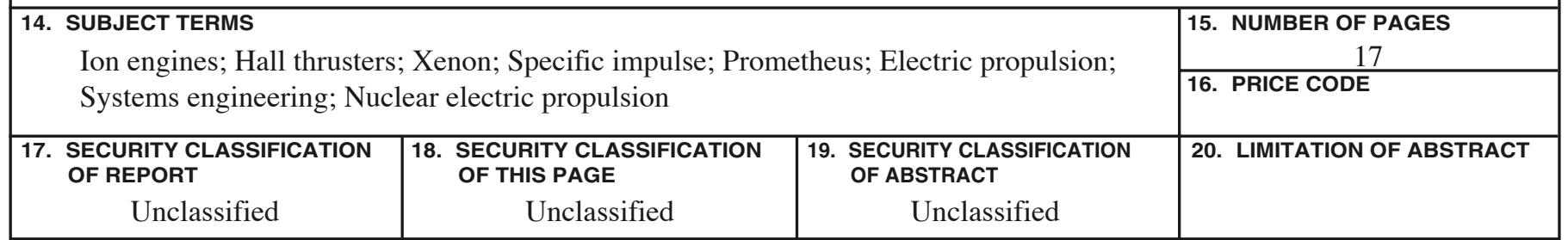



